\title{
Stump tumors: clinical, histological and therapeutic aspects a case report
}

\author{
Houda Moustaide*, Doha Ziane, Ilias Bzioui, Saad Benkirane
} Department of Gynecology and Obstetrics, Faculty of Medicine, Abdelamel Essaadi University Hospital, Tangier,
Morocco

Received: 31 March 2021

Accepted: 01 May 2021

*Correspondence:

Dr. Houda Moustaide,

E-mail: misshouda.med@gmail.com

Copyright: ( ) the author(s), publisher and licensee Medip Academy. This is an open-access article distributed under the terms of the Creative Commons Attribution Non-Commercial License, which permits unrestricted non-commercial use, distribution, and reproduction in any medium, provided the original work is properly cited.

\section{ABSTRACT}

Smooth uterine muscle tumor of uncertain malignant potential (STUMP) belongs to a unique entity that is rare and known by its complexity. Histology is the gold standard for the diagnosis. The aim of the study was to expose the latest researches in the field, about the clinical and radiological aspects to find a way to recognize these tumors way before surgery in order to discuss the best therapeutic strategy, by way of a clinical case report.

Keywords: Smooth muscle tumor, Hysterectomy, Laparotomy, Menorrhagia

\section{INTRODUCTION}

Uterine smooth muscle tumors of uncertain malignant potential (STUMPs), are an extremely rare borderline uterine tumors: $0.01 \%$ of surgical samples of myomectomies or hysterectomies. ${ }^{1,3}$ Their diagnosis is always made after surgery because their clinical and radiological profile is far from being specific. Through our clinical case, we drew attention to the existence of these tumors to assess their clinical and radiological expression, discuss the therapeutic modalities and those of the followup.

\section{CASE REPORT}

This is a 43-year-old patient, married and mother of 2 living children without personal or family medical history, who had suffered for more than 1 year, a moderate to high abundance of menometrorrhagia associated with heaviness-type pelvic pain without digestive or urinary signs. The abdominal examination revealed an enlarged uterus reaching the umbilicus and the speculum examination showed low bleeding from the endocervix with a healthy cervix. The patient had microcytic hypochromic anemia at $7 \mathrm{~g} / \mathrm{l}$ which was corrected by iron supplementation. The patient underwent a pelvic ultrasound which revealed an increased uterus whose measurements exceed the screen with a uterine mass of $12 \mathrm{~cm}$ on a well-limited long axis echogenic and heterogeneous, suggesting a uterine fibroid. The patient underwent a subtotal hysterectomy with adnexal preservation by laparotomy, the operative consequences of which were simple. Pathological examination showed a STUMP (according to the criteria of Bel et al and the WHO 2014 classification).

\section{DISCUSSION}

The majority of uterine smooth muscle tumors are benign, and the risk of a malignant transformation to leiomyosarcomas; is rare; $1 \%$. But there is a variant of these tumors which cannot be described, based on clinical and histological findings, as benign or malignant and that the WHO (OMS) defines as, STUMPs. ${ }^{2}$

Because of their rarity, the risk factors and pathophysiology of STUMPs are poorly understood however some studies which have been made over several 
years have been able to collect over ten cases and determine the epidemiological profile of these patients: The average age at the time of diagnosis was 45 years without medical history nor pelvic irradiation or hormone replacement therapy, and $50 \%$ of the cases were menopausal and $40 \%$ were rated obsese. ${ }^{1-3}$

These tumors are often discovered during the anatomopathological study of the operative parts of myomectomies or hysterectomies for uterine fibroids. It is very hard to come up with the diagnosis only from clinical and radiological examinations because there are no specific symptoms correlated to these tumors, they manifest with variable gynecological signs similar to those seen in benign leiomyomas such as abnormal vaginal bleeding, pelvic pain, or a pelvic mass. In some studies, the most common symptom was menometrorrhagia.,

According to the results of a scientific work focused on 20 smooth muscle tumors of which 18 were STUMP tumors, the results of ultrasound data showed there is a clear difference between benign fibormyomas and STUMP tumors. Unlike benign leimyomas which appear on ultrasound as a uniform hypoechoic image with shadows and peripheral vascularization, ultrasound features of STUMP tumors may occasionally differ slightly from those of leimyomas; most often it is a well-defined intramyometrial image with mixed echogenicity of heterogeneous appearance, and in $70 \%$ of cases it contains anechoic areas of cystic appearance inside of the tumor without calcifications. Doppler showed circumferential vascularization of these myometrial images. Some new researches had shown the superiority of dynamic contrast enhaced MRI when it comes to specific diagnosis of STUMP tumors with $94 \%$ accuracy and $96 \%$ of specificity. ${ }^{3,4}$

Until the present time, there is no therapeutic consensus regarding the management of STUMP tumors, however surgery is the most used option around the world. The surgical procedure consists of a total hysterectomy with or without bilateral adnexectomy whatever the surgical approach is, it represents the standard treatment. Conservative treatment such as myomectomy can be considered in young women with a desire for pregnancy. ${ }^{2,3}$

About hormone therapy and chemotherapy, there are no studies demonstrating their usefulness in these borderline uterine tumors. An extension assessment is usually requested based on thoraco-abdomino-pelvic scanner looking for a secondary location. ${ }^{5}$

Histological examination of the surgical sample, is the key to a positive diagnosis; macroscopically these tumors are often large, the average dimensions are approximately around $6 \mathrm{~cm}$ and the diagnosis of certainty is provided by Bell et al and Ip et al criteria are: the increase in cellularity, cytological atypias, mitotic activity $<10 \mathrm{phf}$ and cell necrosis. In half of the cases, this examen helps to find the coexistence of STUMP tumors with leimyomas and leimyosarcomas. ${ }^{5,6}$

Because of their rarity there is a lake of information regarding STUMP evolution through time. In literature it is known that they present an unpredictable outcome, most behave in a benign manner, although some have a malignant course. Besides the therapeutic strategy that is not standarized, we still don't know how to follow up patients diagnosed with STUMPs. In some studies, they had evaluated the risk of recurrence to: $10.5 \%$ with possibility of malignant recurrence. This is why most of the praticians indicate a regular monitoring by clinical and ultrasound examination every 6 months and a CT-scan every 6 years. and MRI and chest X-ray once a year for 5 years are recommended in case of conservative treatment. $^{5-7}$

\section{CONCLUSION}

STUMP tumors are rare and their clinical and radiological diagnosis is difficult, given the great resemblance with benign leimoyomas. The histological examination is the cornerstone of the positive diagnosis which alone makes it possible to differentiate these borderline tumors from uterine sarcomas. The outcome is often favourable whatever the type of surgical treatment, however there is a risk of malignant transformation, hence the importance of close monitoring of these patients.

\section{Funding: No funding sources Conflict of interest: None declared \\ Ethical approval: Not required}

\section{REFERENCES}

1. Gadducci A, Zannoni GF. Uterine smooth muscle tumors of unknown malignant potential: A challenging question. Gynecol Oncol. 2019;154(3):631-7.

2. Shim JI, Han AKW, Jeon HJ, Kim ML, Jung YW, Yun BS, et al. Clinical experience of uterine smooth muscle tumor of uncertain malignant potential in two gynecological centers: Oncological and obstetrical aspects. Eur J Obstet Gynecol Reprod Biol. 2020;246:7-13.

3. Karataşlı V, Cakır I, Ayaz D, Budak A, Sancı M. Clinicopathologic evaluation of uterine smooth muscle tumors of uncertain malignant potential (STUMP): A single center experience. J Gynecol Obstet Hum Reprod. 2019;48(8):637-42.

4. Cotrino I, Carosso A, Macchi C, Baima Poma C, Cosma S, Ribotta M, Viora E, Sciarrone A, Borella F, Zola P. Ultrasound and clinical characteristics of uterine smooth muscle tumors of uncertain malignant potential (STUMPs). Eur J Obstet Gynecol Reprod Biol. 2020;251:167-72.

5. Han AKW, Hong K, Kim M, Kim MK, Kim ML, Jung $\mathrm{YW}$, et al. Unexpected uterine smooth muscle tumor of uncertain malignant potential and sarcoma: A 
single center cohort study in South Korea. Taiwan J Obstet Gynecol. 2020;59(2):275-81.

6. Jang TK, Kwon SH, Cho CH, Lee HW, Shin SJ. Giant uterine mass with uterine smooth muscle tumor of uncertain malignant potential: A case report. Gynecol Oncol Rep. 2020;34:100663.

7. Ha HI, Choi MC, Heo JH, Kim KA, Jung SG, Park H, et al. A clinicopathologic review and obstetric outcome of uterine smooth muscle tumor of uncertain malignant potential (STUMP) in a single institution. Eur J Obstet Gynecol Reprod Biol. 2018;228:1-5.

Cite this article as: Moustaide H, Ziane D, Bzioui I, Benkirane S. Stump tumors: clinical, histological and therapeutic aspects a case report. Int J Reprod Contracept Obstet Gynecol 2021;10:2486-8. 